\title{
Piercings in medical students and their effects on the skin*
}

\author{
Kátia Sheylla Malta Purim ${ }^{1,2}$ \\ Cristine Secco Rosario ${ }^{2}$
}

Bernardo Augusto Rosario ${ }^{1}$

Ana Tereza Bittencourt Guimarães ${ }^{2}$

DOI: http://dx.doi.org/10.1590/abd1806-4841.20142878

\begin{abstract}
BACKGROUND: Piercings are body embellishments commonly seen in young people, however their inherent risk of infection and scarring disorders are less divulged.

OвJECTIVE: To evaluate the prevalence of body piercings among medical students and their possible dermatologic consequences.

METHODS: Cross-sectional study with 58 medical students, by means of a structured questionnaire covering socio-demographic characteristics, technical issues related to the piercing and characteristics of the dermatologic complications.

RESULTS: The sample was predominantly female (86.2\%), with mean age $24 \pm 3$ years. The placement of the first piercing occurred during adolescence (median age 15), without medical supervision $(91.4 \%)$ or knowledge of parents/guardians (74\%). Most piercings were made of metal alloy/stainless steel, in a dumbbell model $(51.7 \%)$, inserted in the umbilical area $(53.5 \%)$ or ear $(41.4 \%)$, with frequent cutaneous reactions in the first six months postpiercing. Hypertrophic scarring, pain, swelling and infection $(\mathrm{p}<0.05)$ had significantly higher frequencies among those with navel piercings.

CONCLUSION: Piercing insertion occurred during adolescence. Local inflammatory and infectious reactions were common. Scarring disorders and dermatitis appeared in the long term. There is need for preventive and educational activities, starting with those in the academic environment.
\end{abstract}

Keywords: Body piercing; Medical students; Scarring

\section{INTRODUCTION}

For the last decades, the popularity of body piercings has been in expansion in many countries, socioeconomic strata and age groups, with prevalence rates ranging from $25 \%$ to $51 \%$ among adolescents and young adults. ${ }^{1-6}$ In ancient civilizations this accessory entailed military, religious and socio-cultural issues, having sparked prejudice due to a possible association with signs of rebellion and risk behaviors. ${ }^{7-10}$ Currently, its wear is motivated by several factors, mainly the desire to try something new in order to take control of the body and identity, but also by passing trends or fads, influence of friends, inclusion into specific groups, greater acceptance in society and the stimuli provided by the media. ${ }^{1,2,1,12}$

The word "piercing" derives from the English verb "to pierce", which means to transfix and this is a deliberate and somewhat semi-permanent procedure, considered a factor that causes alteration of local homeostasis and exposure to communicable diseases. ${ }^{2,13}$ The risks to piercing wearers are grouped into categories associated with purchase, possession and health care. ${ }^{14}$ The risk stemming from purchase is related to piece's price and the procedure that the individual undergoes to have it inserted. ${ }^{1,6,14}$ As to possession, although the embellishment has a symbolic value to the owner, others may perceive that body symbol in a negative way, with impacts on relationships and self-esteem. ${ }^{7,910,12,15}$ However, attention to health risks is a priority due to the necessity to reduce lesions, increase protection and prevent eventual physical, emotional and cosmetic damages. ${ }^{12,14,15}$

Depending on the body region, manner of insertion and maintenance conditions, the presence of a piercing can justify disorders and adverse effects that may go on for days, weeks or months after implantation. ${ }^{1,6,8}$ The cutaneous areas that are most reaction-prone are the navel, ear and nose. ${ }^{1,14}$ Studies have demonstrated the occurrence of cutaneous infections, cysts, edema, granuloma, hematoma, keloids, hypertrophic scars, abscesses, contact dermatitis and allergic reactions. ${ }^{6,16,17}$ In intra and perioral regions, research evidences: pain, edema, airway obstruction, grooved or fractured teeth, gingival trauma, tongue and lip injuries, interference with mastication, speech and salivation, halitosis, periodontitis and foreign body aspiration. ${ }^{18-20}$ Medical reports of piercing com-

\footnotetext{
Received on 17.06.2013.

Approved by the Advisory Board and accepted for publication on 07.12.2013.

* Work performed at Universidade Positivo (UP) in association with Universidade Federal do Paraná (UFPR) - Curitiba (PR), Brazil.

Conflict of interest: None

Financial funding: None

Universidade Positivo (UP) - Curitiba (PR), Brazil

Universidade Federal do Paraná (UFPR) - Curitiba (PR), Brazil.

CC2014 by Anais Brasileiros de Dermatologia
} 
plications in the pinna include perichondritis, cauliflower deformity, infectious disorders, scarring and various aesthetic deformities. ${ }^{14,20}$ Studies also draw attention to possible systemic outcomes such as bacterial endocarditis, tetanus, hepatitis $\mathrm{B}$ and $\mathrm{C}$, tuberculosis, HIV infection, toxic shock syndrome, osteomyelitis and acute diffuse glomerulonephritis in susceptible individuals. ${ }^{21-28}$

The detrimental aspects of piercing are associated with the lack of knowledge on preventive measures. Body piercing requires universal health precautions and appropriate positioning, in restricted noncartilaginous areas..$^{29-32}$ The decorative piece should be made of surgical stainless steel, gold, titanium or acrylic and regardless of the chosen type, it needs to be removable to be periodically cleansed., ${ }^{1,2,18}$ Approximately $10-30 \%$ of piercing cases present infection or bleeding in the insertion site. ${ }^{1,19,31,33}$ These adornments are contraindicated in pregnant women, immunocompromised patients, those who are prone to keloid formation, infectious dermatitis, atopic dermatitis, and dermographism and also during sports practice. ${ }^{1,18,33}$ Piercings are not recommended to patients with blood dyscrasias, congenital heart disease and those using anticoagulants. ${ }^{1}$ Individuals with piercings, which were implanted in safe sanitary conditions, must wait at least six months to donate blood. ${ }^{1}$ Current law establishes regulations and periodic inspections of tattoo and piercing establishments. ${ }^{1}$ Nevertheless, there is not yet a federal legislation about the insertion of these body adornments in children and adolescents. ${ }^{18}$

Despite frequent patients' complaints on cutaneous reactions and scarring secondary to piercing wear, we realize the need for more research to divulge the risks involved in this practice. This knowledge is important in the medical environment because such situations can have serious physical and emotional consequences, and require specific approaches for their prevention and treatment. ${ }^{1,29,32-35}$ The aim of this study is to evaluate the prevalence of cutaneous piercing and the ensuing consequences among young medical students.

\section{SUJECTS AND METHODS}

This study is a descriptive cross sectional survey research, targeting the population of medical students in a private institution in southern Brazil. The research ethics committee approved this project (protocol number 041/2011) and assured confidentiality and anonymity to the volunteers.

Piercing was defined as any type of adornment (body piercing), jewelry, accessory or decorative piece, inserted in the skin or mucosae, through a probing object (gun, needle, pin, ornament itself, piercing stylus etc.), in different parts of the body other than the earlobes. Ornaments in the second earlobe orifice or the use of earlobe stretching plugs were not considered as piercings.

Assessment of tobacco consumption followed the World Health Organization (WHO) criteria. The emphasis on tobacco was due to its important role in skin healing, with those having smoked a minimum of five packs or 100 cigarettes during their lifetimes defined as smokers, and those who meet the definition of a smoker, but were not current users, as former smokers.

Physical activity was defined according to World Health Organization (WHO) criteria as the completion of at least 30 minutes of moderate intensity exercise on most days of the week.

Sample selection was non-probabilistic, by convenience and occurred through detailed explanations about the research. We initially approached 161 students of both genders and of any color/race/ethnicity, between classes in the university hospital between February and March 2012, on the daily wear of piercings. Those who answered affirmatively were asked to participate in an assessment and screening session for the study. We included 58 volunteers over 18 years old, who had regularly worn piercing for more than six months and agreed to participate by signing the term of free and informed consent, according to Resolution 196/96.

Data were collected through a structured questionnaire, pre-tested by three professors of medicine and applied as a pilot in five students. This data collection instrument was comprised of closed questions to check the students' sociodemographic features such as gender, age, ethnicity, marital status, and behavioral and health aspects, including immunization coverage; and technical issues regarding piercings (type, location, quantity, hygiene procedures). To verify the complications and medical treatments secondary to the piercing procedure, we used clinical and cutaneous data recall, medical history and physical examination. After data collection and assessment, students were informed about preventive measures regarding infections and dermatoses.

The results were analyzed using descriptive statistics, according to the nature of the evaluated variables. Quantitative variables were expressed as means and standard deviations, and categorical variables using absolute and relative frequencies. The absolute frequencies of skin lesions' categorical variables in the different anatomical locations (ear, navel and others) were compared between piercing wearers through the Chi-Square Test for $\mathrm{k}$ proportions, followed by multiple comparisons between analyzed category frequencies by the Marascuilo procedure. The duration of lesions was compared between the groups that worn piercings on ears, navel, ears + 
navel and other sites by variance analysis for a single factor. In all analyzes, we used the significance level of $p<0.05$. These categorical variables were expressed in cross tables and, when necessary, by column charts. All statistical analyzes were performed using the statistical program XLStat2010.

\section{RESULTS}

The sample consisted of 58 students of a private medical institution, who had worn piercings regularly for more than six months. The average age of students was $24 \pm 3$ years; eight were males $(13.8 \%)$ and 50 females $(86.2 \%)$. There was a predominance of Caucasians $(76.8 \%)$, singles $(96.6 \%)$ and those enrolled in the course's $6^{\text {th }}$ or $7^{\text {th }}$ semesters $(51.7 \%)$, (Table 1$)$.

Regarding health features, eight students (13.8\%) had diagnoses of chronic illnesses (asthma, hypothyroidism, rhinitis, epilepsy, myopia, polycystic ovarian syndrome, migraine, psoriasis and depression), and $29(50 \%)$ were taking medications daily, especially contraceptives among women (38\%) and anti-inflammatory drugs in both genders $(16 \%)$. Forty-eight students (82.8\%) were up-to-date with their basic immunization schedule.

As for lifestyle characteristics, six students were smokers $(10.3 \%)$; four of these $(66.6 \%)$ had been smoking for a period 1-5 years and two (33.3\%) smoked more than ten cigarettes per day. Among the subjects analyzed, $27(46.6 \%)$ practiced physical exercises regularly, $85.2 \%$ of them exercised three or more times per week.

TABLE 1: Absolute (FA) and relative frequencies (FR\%) of sociodemographic variables in a sample of piercing wearers $(n=58)$

\begin{tabular}{|c|c|c|c|}
\hline Variables & Category & FA & FR $\%$ \\
\hline \multirow[t]{2}{*}{ Gender } & Feminine & 50 & 86.2 \\
\hline & Masculine & 8 & 13.8 \\
\hline \multirow[t]{4}{*}{ Age (years) } & $20-22$ & 23 & 39.7 \\
\hline & $23-25$ & 28 & 48.3 \\
\hline & $26-28$ & 5 & 8.6 \\
\hline & $>28$ & 2 & 3.4 \\
\hline \multirow[t]{4}{*}{ Race } & Yellow & 3 & 5.2 \\
\hline & White & 43 & 74.1 \\
\hline & Brown & 10 & 17.2 \\
\hline & Did not respond & 2 & 3.4 \\
\hline \multirow[t]{2}{*}{ Marital status } & Married/widow & 2 & 3.4 \\
\hline & Single & 56 & 96.6 \\
\hline \multirow[t]{4}{*}{ Origin } & Curitiba & 29 & 50.9 \\
\hline & Other cities in & 16 & 28.1 \\
\hline & Paraná State & & \\
\hline & $\begin{array}{l}\text { Other cities in } \\
\text { other States }\end{array}$ & 12 & 21.1 \\
\hline \multirow{5}{*}{$\begin{array}{l}\text { Which semester } \\
\text { are you attending? }\end{array}$} & $2^{\text {nd }}-4^{\text {th }}$ & 5 & 8.6 \\
\hline & $5^{\text {th }}-6^{\text {th }}$ & 11 & 19.0 \\
\hline & $7^{\text {th }}-8^{\text {th }}$ & 27 & 46.6 \\
\hline & $11^{\text {th }}-12^{\text {th }}$ & 13 & 22.4 \\
\hline & Did not respond & 2 & 3.4 \\
\hline
\end{tabular}

Assessment of piercing wear characteristics found that, on average, the first adornment was implanted at $14 \pm 3$ years of age, for reasons such as fashion trend $(44.8 \%)$ or willingness to experiment $(25.9 \%)$. The minimum age for piercing insertion was 12 years old, maximum of 23 years and median of 15 years. Thirteen students $(22.4 \%)$ inserted another piercing about a year after the first procedure. The amount of body piercings was one to two (84.2\%), with a preference for metal/stainless steel piercings, in dumbbell shape (51.7\%) located in the navel (53.5\%) or ear $(41.4 \%)$, (Table 2$)$.

About the decision-making process on the piercing insertion, 29 (50\%) students did not seek any information, twenty $(34.5 \%)$ sought information on the Internet, thirteen $(22.4 \%)$ talked about the question with friends and five (8.6\%) requested information from physicians. Fifteen students (26\%) did not discuss the insertion with their parents before the procedure.

In assessing the characteristics of insertion procedures, data showed that body piercing was performed in specialized studios (84.5\%), with qualified professionals (63.8\%). Among the participants in the sample, 27 completed a registration form on the use of piercing (46.6\%) and 32 received leaflets (54.4\%). Upon insertion of the piercing, the professional wore gloves $(94.8 \%)$, disposable materials $(85.4 \%)$, topical anesthetic $(25.9 \%)$, and wound dressings $(26.4 \%)$.

TABLE 2: Absolute (FA) and relative frequencies (FR\%) of variables about reason for wearing and piercing characteristics in the sample $(\mathrm{n}=58)$

\begin{tabular}{llll}
\hline Variables & Category & FA & FR\% \\
\hline Reason & Beauty & 13 & 22.4 \\
& Influenced by friends & 3 & 5.1 \\
& To record an event/time & 2 & 3.4 \\
& Fashion trend & 26 & 44.8 \\
Material & I wanted to & 15 & 25.9 \\
& Silver & 8 & 13.8 \\
& Metal/Stainless steel & 47 & 81.0 \\
& Gold & 8 & 13.8 \\
Model & Plastic & 1 & 1.7 \\
& Ring & 11 & 19.0 \\
& Dumbbells & 30 & 51.7 \\
& Straight & 14 & 24.1 \\
Site & Ball & 8 & 13.8 \\
& Horseshoe & 11 & 19.0 \\
& Mouth/lips & 2 & 3.4 \\
& Tongue & 5 & 8.6 \\
& Nipples & 1 & 1.7 \\
pierced holes & Ear & 24 & 41.4 \\
& Navel & 31 & 53.4 \\
& Nose & 6 & 10.3 \\
& Perineal region & 1 & 1.7 \\
& Eyebrow & 2 & 3.4 \\
& 2 or more & 35 & 60.3 \\
& Did not respond & 13 & 22.4 \\
& & 9 & 15.5 \\
& & 1.7 \\
\hline
\end{tabular}


Regarding hygiene habits, 33 students cleansed the adornment daily (57.1\%), 36 did not change the piercing $(61.4 \%)$ and one of the students changed it daily $(1.8 \%)$. Fifty-three students had worn the piercing for more than five years (91.4\%). None of the 58 students in the sample had clinically apparent record of systemic complications.

Assessment of cutaneous lesions secondary to piercing wear showed that 29 students $(50 \%)$ had local reactions such as infections (55.2\%), pain/swelling/inflammation (37.9\%) and hypertrophic scar/keloids $(24.1 \%)$ in the first six months after the insertion (65.5\%), (Graph 1).

However, when evaluating the therapeutic approach, we observed a spectrum ranging from no intervention at all (41.4\%), use of antibiotics $(13.8 \%)$, antiseptics $(13.8 \%)$, and other ointments $(10.3 \%)$, to removal of the adornment $(10.3 \%)$. Unsightly scars $(20 \%)$ and contact dermatitis $(7.7 \%)$ also developed six months after insertion, requiring specialized and prolonged treatment. In all insertion sites (ear, navel, ear + navel and others) the mean duration time of the lesions was similar, ranging from 2 to 12 months $(7+5$ months) $\left(\mathrm{F}_{3,24}=0.83, \mathrm{p}=0.490\right)$ (Graph 2). Unwanted scars were located mainly in ears and navel.

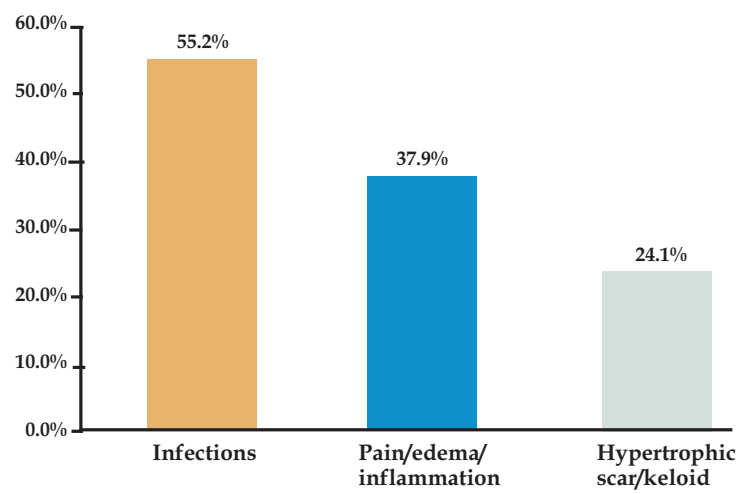

GRAPH 1: Relative frequencies (FR\%) of cutaneous lesions secondary to piercing wear in the first six months after the insertion
Comparisons between lesions arising in different insertion sites demonstrated homogeneity in all categories among piercing wearing groups (Table 3).

\section{DISCUSSION}

In this research, piercings were directly associated with adolescence, since all insertions occurred prior to university admission. Adolescence is a stage of human development, which includes biological, psychological and social changes. ${ }^{1,3}$ The insertion of such embellishments at this stage can be seen as a rite of passage, a style, an ideology or a form of expression, with different understandings and interpretations according to the literature.-12,15,31

Embellishments and body alterations are present throughout the history of mankind and there are several reasons for their practice in the contemporary world. ${ }^{1,18}$ Among the main reasons to wear this accessory are the expression of identity, followed by beauty and fashion..$^{1,11-13,18}$ In this study, we found that the insertion of piercing was influenced by fashion trends and the search for individual and collective affirmation. The need for experimentation, as well as social factors encouraging embellishment and consumption may favor the decision to wear piercings, further fueled by the industry and trade of body products.

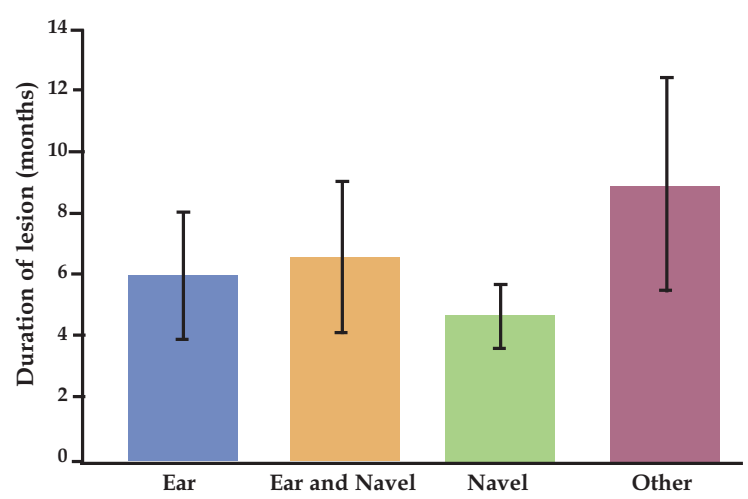

GRAPH 2: Mean duration of lesions secondary to piercing insertion in different body regions

TABLE 3: Absolute (FA) and relative frequencies (FR\%) of variables related to piercing insertion in different body parts

\begin{tabular}{|c|c|c|c|c|c|c|c|c|c|c|}
\hline \multirow{3}{*}{$\begin{array}{l}\text { Variable } \\
\text { Secondary lesion }\end{array}$} & \multirow{3}{*}{$\begin{array}{l}\text { Category } \\
\text { Allergy }\end{array}$} & \multirow{2}{*}{\multicolumn{2}{|c|}{$\begin{array}{l}\text { Ear } \\
(n=16)\end{array}$}} & \multirow{2}{*}{\multicolumn{2}{|c|}{$\begin{array}{l}\text { Ear and navel } \\
(n=6)\end{array}$}} & \multirow{2}{*}{\multicolumn{2}{|c|}{$\begin{array}{l}\text { Navel } \\
(n=29)\end{array}$}} & \multirow{2}{*}{\multicolumn{2}{|c|}{$\begin{array}{l}\text { Other } \\
(n=7)\end{array}$}} & \multirow[t]{2}{*}{$\mathbf{p}$} \\
\hline & & & & & & & & & & \\
\hline & & 2 & $12.5 \%$ & 0 & $0 \%$ & 2 & $13.3 \%$ & 0 & $0 \%$ & 0.627 \\
\hline & Hypertrophic scar & 2 & $12.5 \%$ & 2 & $40 \%$ & 4 & $26.7 \%$ & 2 & $66.7 \%$ & 0.53 \\
\hline & Pain & 3 & $18.8 \%$ & 2 & $40 \%$ & 4 & $26.7 \%$ & 2 & $66.7 \%$ & 0.63 \\
\hline & Edema & 3 & $18.8 \%$ & 2 & $40 \%$ & 4 & $26.7 \%$ & 2 & $66.7 \%$ & 0.639 \\
\hline & Infection & 3 & $18.8 \%$ & 2 & $40 \%$ & 9 & $60 \%$ & 2 & $66.7 \%$ & 0.825 \\
\hline & Bleeding & 1 & $6.3 \%$ & 0 & $0 \%$ & 0 & $0 \%$ & 0 & $0 \%$ & 0.445 \\
\hline & Contact dermatitis & 2 & $12.5 \%$ & 0 & $0 \%$ & 2 & $6.9 \%$ & 0 & $0 \%$ & 0.627 \\
\hline & Unsightly scar & 2 & $12.5 \%$ & 2 & $33.3 \%$ & 7 & $24.1 \%$ & 1 & $14.3 \%$ & 0.654 \\
\hline
\end{tabular}


In the present investigation, there was a prevalence of $58(36 \%)$ piercing wearers among 161 students that were approached. This result differs from the studies performed with Portuguese (18\%), Venezuelan (28\%) and American (51\%) students, which can be attributed to methodological, demographic and sociocultural variations. ${ }^{2,6,19}$ Only the Portuguese study matched the characteristics of the sample described here. ${ }^{19}$

The largest proportion of piercings among females, although consistent with the literature ${ }^{1}$, can be related in our research to the growing presence of women in medical courses and the social expectation on the maintenance of aesthetics and beauty standards ${ }^{12}$. The quantity of one to two perforations and the preference for metal adornments was similar to findings by other authors. ${ }^{1,6,16}$

The most widely used anatomical site for piercing insertion in the studies with Portuguese and Venezuelan medical students was the pinna, whereas in the present study, the navel region predominated. ${ }^{6,19}$ A likely explanation is the peculiarity of the Brazilian social relations, which are expressed through the body and physical appearance. Another reason is the opportunity to show or conceal the existing embellishment in the abdomen. The choice of the navel as a location can still suggest the appraisal for a wellformed and sensuous female figure.

Studies consider piercings as possible indicators of situations involving smoking, alcohol and drug abuse. ${ }^{711,12}$ In this study, daily smoking was observed in three women and three men, with durations ranging from 1-12 years. Two (33\%) of these six students had skin lesions secondary to the piercing insertion, probably by the action of nicotine on the healing process, in addition to constitutional factors. Educational actions on protection and resilience were suggested to prevent these young people to maintain or initiate the smoking habit during university.

A research conducted on the detection of drug abuse among Brazilian medical students indicated the need to take preventive measures. ${ }^{34}$ In this study, we did not specifically address the issue of alcohol and illegal drugs, however, the tendency to over-medication verified among the students drew our attention. On the one hand, the rational use of medications during the medical training years can assist in the proper management of patients afterwards, when these students are practicing their profession. However, environmental contamination with medication waste and abuse of psychoactive drugs, are considered problems of great magnitude nowadays. ${ }^{34}$

The priorities, in programs of integral attention to youth and adolescents, are health promotion and dis- ease prevention to minimize future consequences. ${ }^{1,19,32}$ Although wearing piercing is a personal choice, exaggerated body modifications should be observed with caution, so that one can differentiate an identity crisis or fashion fad from psychoaffective disorders. ${ }^{7,8,2,31}$ These situations require ethical and sensible approaches, dissociated from discriminatory perceptions, and aimed at reinforcing dialogue and consolidating trust bonds. ${ }^{1}$

The lack of straightforward and specific instructions on the risks of piercing wear exposes individuals to the vulnerability of procedures performed by unqualified personnel, which is a global concern. ${ }^{6,12}$ Research shows that inadequate sanitation, poor technique, inappropriate material and insertion in areas subject to friction favor complications. ${ }^{25,26,29} \mathrm{In}$ the present study, infection and scarring disorders, as well as pain and edema were frequent, especially in individuals with navel piercings, but without statistically significant differences with other regions $(p>$ 0.05). Such situations are likely to be influenced by the foreign body presence; length of wound re-epithelialization and friction caused by clothing.

Piercing materials containing nickel or chromium may cause dermatitis by irritation or sensitization. The individual, who insists on keeping the adornment even with dermatitis, cannot however foresee the development of hypersensitivity. ${ }^{35}$ In this investigation, a student had allergic sensitization to nickel confirmed by patch testing.

Unsightly scars, caused by the piercing procedure with the purpose of making openings or holes to insert jewelry in that space, can cause physical, social and psychological discomfort. ${ }^{1,14}$ In this study, we observed that, in twelve students $(20.6 \%)$ the scarring disorders had physical, psychosocial and economic consequences.

Since the use of piercing has become increasingly frequent, physicians need to have correct information and guidelines so they can warn and instruct patients and treat conditions and consequences imposed by bodily adornments. It is essential to have the proper training to correct unsightly scars when the patient wants to remove unwanted marks, as well as dexterity to remove piercings, particularly intra-and perioral, in case of complications and emergencies such as traumas. ${ }^{1,18}$ By following the technical norms of safe surgical practice standards, it is possible to prevent potential exposure to contamination by secretions or accidents related to the application of electrosurgery in patients carrying metal objects. ${ }^{1,14}$

Notwithstanding the limitations of this study regarding its design and sample size, this research emphasizes the need to better educate the public, especially medical students, about the complications secondary to piercing wear. ${ }^{19,24,25}$ The importance of this 
work lies in finding that the decision to insert the piercing occurred most often in an uninformed way, by minors, without seeking medical guidance or parental consent. Another important fact to stress is that this type of procedure is not harmless, since it produces local and systemic unwanted effects, as well as economic and emotional costs. Preventive measures must be known, understood and practiced systematically by the subject and by all professionals involved before, during and after the piercing insertion.

Facing all the potential problems that can be generated by piercing wear, further investigations with a larger number of participants and a control group matched by gender and age, can provide infor-

\section{REFERENCES}

1. São Paulo (Cidade). Secretaria da Saúde. Coordenação de Desenvolvimento de Programas e Políticas de Saúde- CODEPPS. Manual de atenção à saúde do adolescente. São Paulo: SMS; 2006. 328p.

2. Mayers $L$, Chiffriller S. Sequential Survey of Body Piercing and Tattooing Prevalence and Medical Complication Incidence Among College Students. Arch Pediatr Adolesc Med. 2007;161:1219-20.

3. Cegolon L, Mastrangelo G, Mazzoleni F, Majori S, Baldovin T, Xodo C, et al. Body Art in 4,277 Italian Secondary School Adolescents: Prevalence and Associations with Personal and Family Characteristics. Fam Med. 2010;42:273-9.

4. Gutsche P, Schmalz G, Landthaler M. Prevalence of piercing in a German population. Eur J Dermatol. 2008;18:26-8.

5. Mayers LB, Judelson DA, Moriarty BW, Rundell KW. Prevalence of Body Art (Body Piercing and Tattooing) in University Undergraduates and Incidence of Medical Complications. Mayo Clin Proc. 2002;77:29-34.

6. Misticone S, Kannee C, Ortiz W, Alio A, Ortega J. Tatuajes y perforaciones corporales: qué tan frecuentes son? Dermatol Venez. 2004;42:18-21.

7. Yen CF, Hsiao RC, Yen JY, Yeh YC, Wang PW, Lin HC, et al. Tattooing among high school students in southern Taiwan: the prevalence, correlates and associations with risk-taking behaviors and depression. Kaohsiung J Med Sci. 2012;28:383-9.

8. Huxley, Grogan S. Tattooing, Piercing, Healthy behaviours and Health Value. J Health Psychol. 2005;10:831-41.

9. Ekinci 0, Topcuoglu V, Sabuncuoglu O, Berkem M, Akin E, Gumustas FO. The association of tattooing/body piercing and psychopathology in adolescents: a community based study from Istanbul. Community Ment Health J. 2012;48:798-803.

10. Schorzman CM, Gold MA, Downs JS, Murray PJ. Body art: attitudes and practices regarding body piercing among urban undergraduates. J Am Osteopath Assoc. 2007;107:432-8.

11. Stirn A. Body piercing: medical consequences and psychological motivations Lancet. 2003;361:1205-15.

12. Ribeiro PCP, Oliveira PBR. Culto ao Corpo: beleza ou doença? Adolesc Saúde. 2011;8:63-9.

13. Mayers LB, Chiffriller SH. Body Art (Body Piercing and Tatooing) Among Undergraduate University Students:"then and now". J Adolesc Health. 2008;42:201-3.

14. Uptodate.com [Internet]. Schmidt RM, Armstrong ML. Body piercing in adolescents and young adults [cited 2013 May 20]. Available from: http://www.uptodate.com/contents/body-piercing-in-adolescents-and-young-adults

15. Antoszewski B, Sitek A, Fijałkowska M, Kasielska A, Kruk-Jeromin J. Tattooing and body piercing--what motivates you to do it? Int J Soc Psychiatry. 2010:56:471-9.

16. Martínez JC. Efectos indeseables de la aplicación de piercings y tatuajes. Dermatología Rev Mex. 2009:53:219-24.

17. Mataix J, Silvestre JF. Cutaneous adverse reactions to tattoos and piercings. Actas Dermosifiliogr. 2009;100:643-56.

18. Lise MLZ, Cataldo Neto A, Gauer JGC, Dias HZJ, Pickering VL. Tattooing: profile and discourse of individuals with marks in the body. An Bras Dermatol. 2010:85:631-8.

19. Cesar RMR. Estudo das perspectivas da utilização de piercings e tatuagens por uma população de estudantes universitários na área de medicina dentária [dissertação]. Porto, Portugal: Universidade Fernando Pessoa; 2011. 45p. mation to health professionals, parents, educators and legislators to prioritize preventive measures and improve the quality of care and conduct.

\section{CONCLUSIONS}

The prevalence of body piercing among these medical students was high, especially in females. Local complications were frequent and predominated in the first six months after the procedure, especially in those students with navel piercings. Infectious and inflammatory processes marked the acute reactions, while chronic reactions were related to scarring disorders and contact dermatitis.]

20. Fernandez AP, de Castro Neto I, Anias CR, Pinto PCL, de Carvalho e Castro J, Carpes AF. Post-piercing perichondritis. Rev Bras Otorrinolaringol 2008;74:933-7.

21. Giuliana B, Loredana S, Pasquale S, Giovanna P, Giorgio C, Laura C, et al. Complication of nasal piercing by Staphylococcus aureus endocarditis: a case report and a review of Literature. Cases J. 2010;3:37

22. Ranga N, Jeffery AJ. Body piercing with fatal consequences. BMJ Case Rep. 2011;2011. pii: bcr0520103020.

23. Bone A, Ncube F, Nichols T, Noah ND. Body piercing in England: a survey of piercing at sites other than earlobe. BMJ. 2008;336:1426-8.

24. Antoszewski B, Szychta P, Fijałkowska M. Are we aware of all complications following body piercing procedures? Int J Dermatol. 2009;48:422-5.

25. Horii KA, Jackson MA. Images in clinical medicine. Piercing-related nontuberculous mycobacterial infection. N Engl J Med. 2010;27;362:2012.

26. Kumar Ghosh S, Bandyopadhyay D. Granuloma pyogenicum as a complication of decorative nose piercing: report of eight cases from eastern India. J Cutan Med Surg. 2012;16:197-200.

27. Meltzer DI. Complications of body piercing. Am Fam Physician. 2005;72:2029-34.

28. Suris JC, Jeannin A, Chossis I, Michaud PA. Piercing among adolescents: body art as risk marker. J Fam Pract. 2007;56:126-30.

29. Holbrook J, Minocha J, Laumann A. Body piercing: complications and prevention of health risks. Am J Clin Dermatol. 2012;13:1-17.

30. Gallè $F$, Mancusi C, Di Onofrio V, Visciano A, Alfano V, Mastronuzzi R, et al Awareness of health risks related to body art practices among youth in Naples, Italy: a descriptive convenience sample study. BMC Public Health. 2011;11:625.

31. Kaatz M, Elsner P, Bauer A. Body-modifying concepts and dermatologic problems: tattooing and piercing. Clin Dermatol. 2008;26:35-44.

32. Lieberman A, Harris D. Acknowledging adult bias: a focus-group approach to utilizing beauty salons as health education portals for inner-city adolescent girls. Health Promot Pract. 2007;8:205-13.

33. Armstrong ML, Roberts AE, Koch JR, Saunders JC, Owen DC. Investigating the Removal of Body Piercings. Clin Nurs Res. 2007:16:103-18.

34. Tockus D, Gonçalves PS. Detecção do uso de drogas de abuso por estudantes de medicina de uma universidade privada. J Bras Psiquiatr. 2008:57:184-7.

35. Brandão MH, Gontijo B. Contact sensitivity to metals (chromium, cobalt and nickel) in childhood. An Bras Dermatol. 2012;87:269-76.

MAILING ADDRESS:
Kátia Sheylla Malta Purim
Universidade Positivo - Curso de Medicina
Rua Professor Pedro Viriato Parigot de Souza, 5300
Campo Comprido
81280-330 - Curitiba -PR
Brazil
E-mail:kspurim@gmail.com

How to cite this article: Purim KSM, Rosario BA, Rosario CS, Guimarães ATB. Piercings in medical students and their effects on the skin. An Bras Dermatol. 2014;89(6):905-10. 